\title{
Towards a line-of-sight, implementation of performance measurement by road agencies: a European and Western Australian perspective
}

\author{
Rob Schoenmaker \\ Faculty of Civil Engineering, \\ Delft University of Technology, \\ Jaffalaan 5, Delft, the Netherlands \\ Email: r.schoenmaker@tudelft.nl
}

\section{Telli van der Lei*}

Faculty of Technology, Policy and Management, Delft University of Technology,

Jaffalaan 5, Delft, the Netherlands

Email: t.e.vanderlei@tudelft.nl

*Corresponding author

\begin{abstract}
This paper is the result of an international, explorative study of the alignment of government and road authority goals from different European countries and Western Australia. The goal of the study is to advance the understanding of the development of performance management of road agencies. Agencies around the world are using performance management to direct transportation investments, support their governments' priorities, and provide greater accountability to the public. The focus of this study is on the alignment of performance management between government and the road agency. In order to compare the alignment between the different countries a reliability, availability, maintainability, safety, security, health, environment, economics and politics (RAMSSHEEP) categorisation based on systems engineering was used. Special attention was paid to the analysis of a 'line-of-sight' and possible criteria to use for the alignment. We find that in most cases the government objectives are not clearly aligned with agency objectives and performance areas of the agency. This limited line-of-sight is a complicating factor in the determining the effectiveness of the performance measures at government level.
\end{abstract}

Keywords: performance measurement; performance management; transportation; infrastructure; highways; Australia.

Reference to this paper should be made as follows: Schoenmaker, R. and van der Lei, T. (2015) 'Towards a line-of-sight, Implementation of performance measurement by road agencies: a European and Western Australian perspective', Int. J. Strategic Engineering Asset Management, Vol. 2, No. 4, pp.370-394. 
Biographical notes: Rob Schoenmaker is an Assistant Professor of Asset Management at Delft University of Technology, Netherlands, since 2011. Before that, he worked for the Dutch Road Agency. He holds a PhD (2011) in Technology, Policy and Management. He teaches various courses in the Master Construction Management and Engineering at the Faculty of Civil Engineering and Geosciences. The focus of his research is on questions related to the effective and efficient application of (outsourced) asset management and performance management.

Telli van der Lei is an Assistant Professor Strategic Engineering Asset Management at the Energy and Industry Section of the Faculty of Technology Policy and Management at Delft University of Technology. Her research is rooted in operations research and focuses on model-based decision support for energy and industry. A large part of the research is done in collaboration with industry. She runs the Next Generation Infrastructures Asset Management Platform, a platform for asset management professionals and academics in the Netherlands. She is the Editor of the book Asset Management: The State of the Art in Europe form a Life Cycle Perspective published by Springer.

This paper is a revised and expanded version of a paper entitled 'Performance Management practices in Europe and the USA' presented at The 93rd Annual Meeting of the Transportation Research Board, Washington, DC, USA, 12-16 January 2014.

\section{Introduction}

\subsection{The need}

Since the 1980s, new public management reforms have paved the way for using performance measurement (PM) in the transport/road sector around the world. The application of PM within road authorities has grown accordingly (see e.g., Queiroz and Kerali, 2010). Not only have many road authorities around the world become road agencies that report to government, at the same time road authorities have also moved towards the use of performance-based contracts for the construction, renewal and maintenance of their assets. Governments increasingly act as owners of the assets, setting high levels objectives for the asset systems and leaving the management of the (road) assets to the road agencies. For example, the Dutch road authority, Rijkswaterstaat (RWS), became an agency in 2006. At the same time, the use of a service level agreement (SLA) between the central government and the agency was introduced. For this SLA key performance indicators were developed. In line with the international trend of outsourcing, RWS also started to move from prescriptive contracts to more performance-based contracts basing their specifications on the RAMS approach from the field of systems engineering. In order to get a more comprehensive set of specifications, RWS expanded the approach to RAMSSHEEP. The outsourcing of asset management activities created the need for more detailed functional and performance specifications for (parts of) the network at the level between the agency and the service providers. Similar trends have been observed in many road agencies in Europe.

This need for PM is emphasised by the definition of asset management in the new ISO 55000 series. This standard was still to be published at the time of this research, but 
the preliminary version of this new ISO standard defines asset management as the "coordinated activities of an organisation to realise life cycle value from assets in delivery of its objectives" (BSI Group, 2012). This preliminary version continues to state: 'A key feature of asset management is the alignment or traceability of activities undertaken on assets to the organisational objectives'.

We use the concept line-of-sight as a short form for the visibility or traceability of performance measures or activities to the organisational objectives across different organisational levels. Three different organisational levels are illustrated in Figure 1. These levels are involved in a line-of-sight from the government objectives to the activities that are performed in the networks that the road agency manages. We use the acronym L1 for the government level, L2 for the level of the road agency, and L3 for the level of the service provider. The line-of-sight needs to be maintained within and between the three levels and is illustrated by the arrows.

Figure 1 Levels involved in a line-of-sight

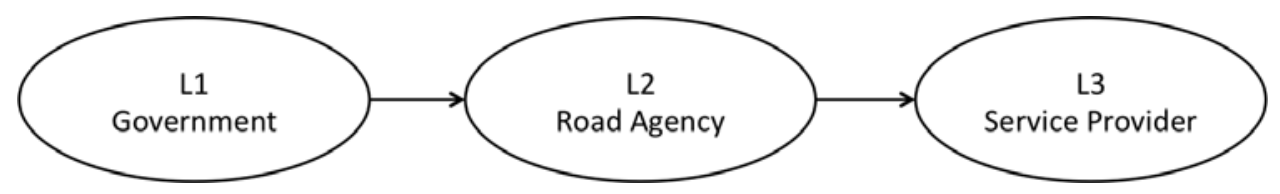

To show this line-of-sight a performance management system is needed. A performance management system that is misaligned or has a lack of alignment may lead to activities that do not contribute to the agency or government objectives. In general, these performance management systems can be used by road agencies to:

1 establish goals and performance targets to manage, explain, deliver, and adjust their roads budgets and internal activities

2 establish effective and achievable performance levels

3 demonstrate good governance and accountability (Queiroz and Kerali, 2010).

What governments and road agencies should aim for is alignment of objectives across organisational levels to prevent the spending of budgets on activities that do not contribute to the government objectives.

Most research on performance management lists the used performance measures (mostly at L2 or between L2 and L3) and a description of the structure and definition of the performance measures (e.g., FHWA, 2010; Karlaftis and Kepaptsoglou, 2012; NCHRP, 2006, 2009, 2010; Schraven et al., 2011) These studies lack information about the alignment of objectives across the various levels. For example, the NCHRP describes performance measures suitable to asset management and develops a framework for establishing performance measures and setting targets (NCHRP, 2006). NCHRP (2010) describes current private- and public-sector practices for performance-based resource allocation, the key elements of the performance-measurement, the tools, data-management systems, and institutional relationships needed to support these elements (NCHRP, 2010). The NCHRP also reports on how transportation agencies can expand and improve the use of performance measures in decision-making (NCHRP, 2009). The FHWA lists the performance measures and application in the USA, Australia (three states), New Zealand, Sweden and England (FHWA, 2010). Karlaftis and 
Kepaptsoglou (2012) focus on reviewing performance requirements and indicators established by developed countries worldwide. The report does not go into detail concerning the actual usage of PM within those agencies. The examples stated above are in line with most literature on performance management that is predominantly focused on finding the appropriate performance measures (Verweire and van den Berghe, 2004). In general, little attention has been paid to the use and experience with PM across the levels mentioned in Figure 1. If so, it has been done within the level of an asset manager like in NCHRP (2012), which focuses on how state departments of transport actually use PM to manage their highway maintenance and operations programmes. Or it has been done between the levels of asset manager and service provider (L2-L3) (e.g., Altamirano, 2010; Koppinen and Lahdenpera, 2004; Pakkala et al., 2007; Schoenmaker et al., 2011) and not between the government as asset owner and the road agency as asset manager (L1-L2). We aim to fill this gap by providing a state of the art overview of the use of PM by road agencies in Europe. This overview will advance the understanding of performance management for road agencies and will help road agencies to learn how to improve performance management across different levels of organisation by looking at the experiences of a number road agencies and how they have used performance management to manage their road network.

In this paper, we focus on the line-of-sight between government and road agency L1 and L2 and within L2, the road agency. This alignment of activities to the organisational objectives is object of our research. While the definition of the organisational objective is a challenge in itself, the extent to which a line-of-sight has been achieved between highlevel objectives and decisions for creating, acquiring, utilising, operating, maintaining and disposing assets is the object of our research.

\section{Approach}

\subsection{What is PM?}

In general, PM is the process of quantifying the efficiency and effectiveness of purposeful action and decision-making (Waggoner et al., 1999). PM can have several positive functions. Performance can be measured in order to enable organisations to (Bouckaert and Auwers, 1999; de Bruijn, 2006; van Dooren, 2006):

- Create transparency: PM leads to transparency and it is an incentive for innovation.

- Learn: PM promotes learning and improving.

- Compare: PM gives opportunities for comparing and benchmarking.

- Assess: PM facilitates assessments.

- Sanction: PM enables sanctioning.

The functions above are mentioned in an increasing order of coerciveness for the party whose performance is measured. It is important to be aware of these various functions of PM and their coerciveness. To preserve the fairness of the PM system, the originally intended functions should not be changed without prior consent of the party whose performance is measured. For example, a system that has been setup to create 
transparency should not be used for sanctioning without consent from the party that is being measured. An important law for the use of PM is the law of decreasing effectiveness: the higher the coercion, the less effective PM will be (de Bruijn, 2007).

Two others aspects of PM are important to note. First, PM systems are never complete: not all aspects of reality can be covered by a measurement system, providing room for strategic behaviour. Second, PM leads to perverse effects or dysfunctional consequences. To identify occurrence of these perverse effects, one needs to look further than the structure of the PM systems.

These perverse or dysfunctional effects are more likely to occur when PM is used in a highly coercive way, like sanctioning. Examples of perverse effects are (Smith, 1995; van Dooren 2006; de Bruijn, 2007):

- single sided focus on what is measured: tunnel vision, near sightedness, target fixation

- strategic behaviour: misrepresentation, misinterpretation, ratchet effect

- loss of ambition

- decreasing effectiveness because of focus on indicators

- wearing down because of positive and negative learning

- collective blindness and ossification.

More detailed examples in a road management context can be found in Altamirano (2010) and Schoenmaker (2011).

Knowledge of these possible perverse effects will help to recognise the (possible) negative experiences with PM and to identify promising strategies to mitigate the effects.

The quality of the individual performance indicators is also of great importance for the successful use of a PM system. Three general requirements identify the quality of each indicator (Bouckaert and Auwers, 1999):

- Validity and reliability: The indicator has to be measurable; it has to accurately capture the intended performance and do so time after time.

- Legitimacy: The indicator has to be accepted by the party that is being measured, the degree to which this party can influence the indicator is most relevant for this acceptance

- Functionality: The indicator has to be relevant, functional. The indicator has to contribute to the higher, more abstract goals.

Validity, legitimacy and functionality contribute to the acceptance of the performance measures by those who are measured, and thus reducing the likelihood of perverse effects.

The key principle of the structure of the performance measures ranging from top-level indicators of government goals to road agency performance measures is that they are aligned in a hierarchical way. This premise is based on value focused thinking (Keeney, 1996) that states that a high level goal should have at least two lower level (sub-)goals (with indicators to measure performance). Looking bottom-up, this means that every top-level indicator is composed of more than one lower level indicator. This top-level is a composite indicator formed, as defined by OECD (2008) when individual 
indicators are compiled into a single index on the based of an underlying model. This underlying model may consist of normalisation and some form of weighting of the individual indicators (Hall et al., 2004; Hodkiewicz et al., 2013; OECD, 2008)

\subsection{Identifying alignment}

In order to detect a line-of-sight from government objectives to performance measures and to be able to compare the results across the various countries, a form of categorisation is needed We choose to use the RAMS approach (CENELEC, 1999) as a basis for categorising the objectives and performance measures and extended it to RAMSSHEEP. The acronym RAMS stands for reliability, availability, maintainability and safety. The RAMS approach for making performance requirements stems from the system engineering (SE) approach (INCOSE, 2010). In SE, once the solutions to fulfil the functional requirements have been chosen, RAMS performance requirements are set for the objects that are part of that solution. The Dutch road agency has embraced SE as the method to design their infrastructure and successfully uses the RAMS approach in their DBFM (RWS, 2009) and performance-based maintenance contracts (only in Dutch and not publicly available). In order to get a more comprehensive overview of their objectives, the agency has expanded the approach to RAMSSHEEP. The extra letters in the acronym stand for security, health, environment, economics and policy. We adopted this approach and the results of the survey will also be used to test the applicability of the RAMSSHEEP approach to describe the alignment between high-level government objectives and agency performance measures. Based on the answers of the survey we decided to add customer satisfaction as an extra category to this approach.

\subsection{The survey}

As ISO 55000 states: a key feature of asset management is the alignment or traceability of activities undertaken on assets to the organisational objectives' (BSI Group, 2012). To show or guide this alignment a performance management system is needed. A poor performance management system leads to ineffectiveness and activities that do not contribute to the agency or government objectives.

The area of PM between the government (L1) and road agency (L2) is underdeveloped in literature and experience and evaluation of PM and management is lacking at this level. The most appropriate way to gather information about the use PM at various road agencies across Europe was to use a survey (questionnaire). The survey was therefore designed to look at the objectives, use, experience and evaluation of PM and management at the L1-L2 level and within the L2 level.

The complete questionnaire of survey is shown in the Appendix and the framework is summarised in Table 1.

- Part 1-General information: This part deals with the identification of the road agency and the respondent.

- Part 2-Performance management-objectives identified: In order to say something about the clarity and alignment of the government and agency objectives the objectives of each have to be identified, including the responsibility and accountability of the road agency 
- Part 3-Performance measures identified: The objectives of the road agency are abstract concepts that need to be operationalised, via aspects (performance areas) into measurable indicators. Next to that, it is important to identify what the responsibility and accountability of the road agency is. The questions in part three focus on this operationalisation of performance measures within the road agency. These questions are not only used to identify the performance measures of the road agency, but also to assess if a certain weighing, a relative importance, is given to each of the indicators and if and how targets are being set.

- Part 4-Performance measures application: Based on the previous questions we now know the structure of PM. But how are these indicators used and for what? This refers to the possible functions and applications of PM as mentioned before.

- Part 5-Performance management evaluation: Knowing the function of the indicators is useful information for this part. This part looks at the positive and negative experiences with using performance indicators. This part also identifies whether the performance measures are used for continual improvement, or in other words, for closing the plan-do-check-cycle (Deming circle). The survey does not include questions to produce answers that are detailed enough to make valid conclusions on the quality of individual indicators used by the surveyed countries. It is the awareness of these requirements that makes the identification of perverse effects easier.

Figure 2 Focus of the questions from the survey

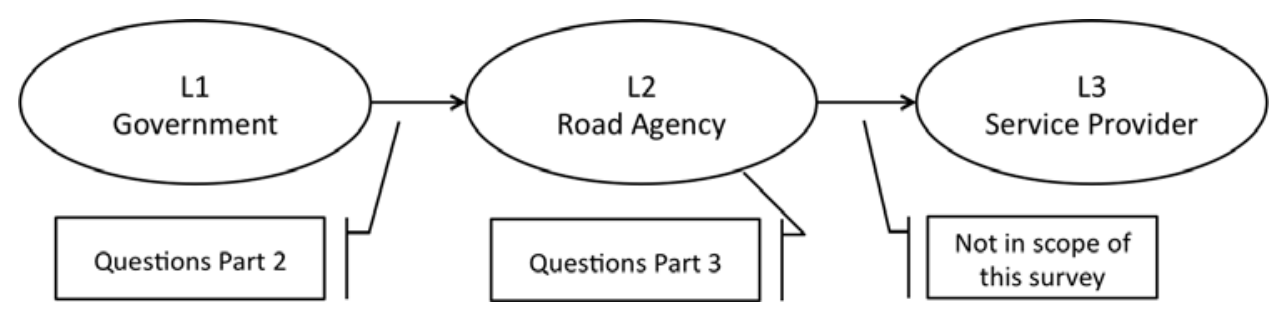

Table 1 Summary of research framework

\begin{tabular}{lcc}
\hline Elements & Reporting & Questions \\
\hline Objectives identified & RAMSSHEEP categorisation & Part 2 \\
Performance measures identified & RAMSSHEEP categorisation & Part 3 \\
Performance measurement application & Functions & Part 4 \\
Performance measurement evaluation & Deming circle & Part 5 \\
\hline
\end{tabular}

\subsection{Selection of survey candidates}

The selection of the road agencies was done based on previous cooperation with experts in these European countries in the area of transportation asset management research (e.g., FEHRL, OECD). Based on our knowledge of the performance management system within Main Roads Western Australia (MRWA), and because our aim is to we decided to include this agency in our survey. The survey was sent to senior managers in asset management or asset planning departments from these agencies. From the total of 
seventeen road agencies that we approached nine of them completed our survey, see Table 2). Only the completed responses are taken into account in the data analysis of the research.

Table 2 Countries/state with completed responses

\begin{tabular}{|c|c|c|c|c|c|}
\hline \multicolumn{6}{|c|}{ List of responding countries/state(s): } \\
\hline 1 & Australia & 4 & Finland & 7 & Lithuania \\
\hline 2 & Austria & 5 & Germany & 8 & Netherlands \\
\hline 3 & England & 6 & Ireland & 9 & Scotland \\
\hline
\end{tabular}

Note: All are national road agencies with the exception of Australia.

\subsection{Timeline of the survey}

The survey was conducted in from October 2012 to April 2013.

\section{Results}

The results provided here have been collected through the responses from the survey see Appendix for overview of the questions. All tables in this section are based on the statements and responses from the survey.

\subsection{L1 government objectives}

The areas for government objectives differ widely per country. Table 1 lists the different areas for the government goals. The table is structured according to the RAMSSHEEP approach with the added objective of customer satisfaction, as a large number of road agencies have measures related to the user of the infrastructure.

Categorising the government goals from the survey according to RAMSSHEEP turned out to be open to interpretation. E.g., we categorised Finland's goal of well-functioning network under' reliability' and 'availability'. Other government objectives cannot be categorised according to RAMSSHEEP. Some examples:

- Information: Various governments mention the provision of information as a government goal, e.g., Austria and the Netherlands.

- Economic growth: Goals that fall under this heading are listed by Australia (state building, focus on regions), England (create growth) and Germany (competiveness), Scotland (wealthier)

- Social goals: Austria and Australia mention more social or social responsibility as a government objective. Is this the same as the Scottish goal fairer distribution of wealth?

Generally speaking the government objectives focus on safety and environmental criteria plus economic, social and information aspects. These are not all covered by the RAMSSHEEP categorisation. In addition, the economic aspect in the categories stands for economic efficiency not economic development and growth. 
Table 3 Overview of L1 government objectives per country

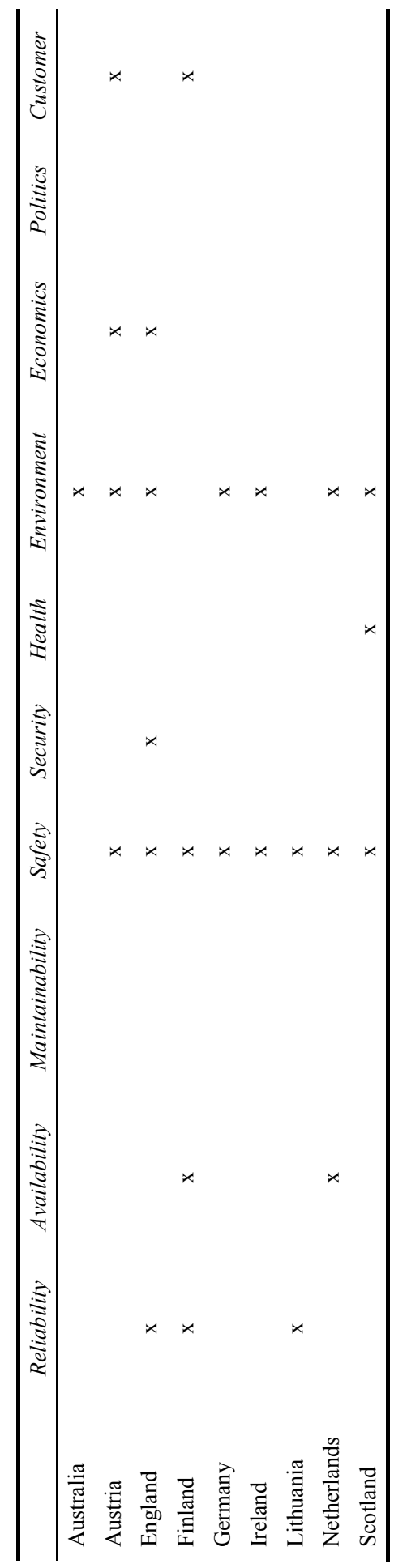


Table 4 Overview of L2 road agency objectives per country

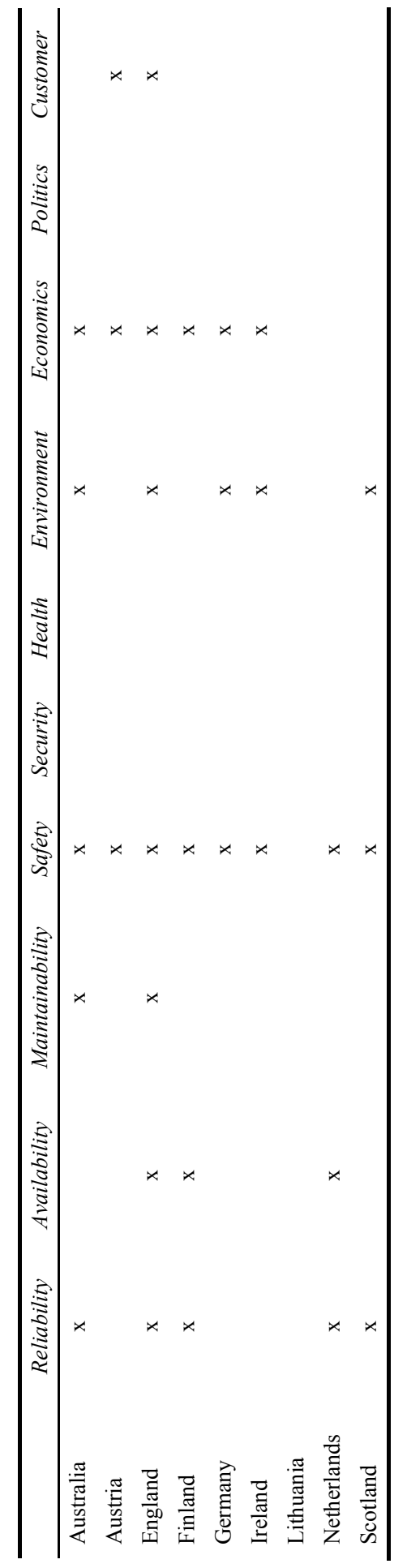


Some countries also specify in the objectives how these objectives are to be achieved. For instance, the Scottish Government has made their objective one step smarter by identifying the critical success factors for achieving the objectives (these are not listed in Table 3. E.g., the objective of a wealthier and fairer Scotland is linked to making journey times faster, more reliable and efficient. The Irish Government goals mention how these goals are to be achieved, firstly by the creation of a road network and secondly to ensure adequate maintenance of that road network. The Lithuanian objective is rather narrow; it specifically mentions winter conditions. The German objectives explicitly state the fair and comparable conditions for all modes of transport.

\subsection{L2 road agency objectives}

When aiming for a line-of-sight, road agency objectives should be deduced from the government objectives. Table 4 shows the objectives of the road agencies.

Limitations of the categorisation show when looking at the organisational goals of the road agencies. First, any agency objectives are too broad to fall under one category. E.g., the Dutch and Finnish objective of 'smooth travel' or the English objective of a strategic road network which supports and facilitates economic growth. Second, categorising the objectives is open to interpretation. England's goal of an efficient and effective network has been categorised under 'reliability' and 'availability'. Third, several objectives do not fall under any category. For example: being the world's leading road operator (England), the provision of information (Austria, and Netherlands) and better journey times (Scotland).

\subsection{L2 road agency responsibilities}

An important requirement for a good performance measure is the legitimacy of that measure which should be closely related to the responsibility of the agency involved. The responsibilities of the different road agencies are depicted in Table 5.

Table 5 Road Agency responsibilities, L2 responsibilities

\begin{tabular}{|c|c|}
\hline Country & Road agency responsibilities: \\
\hline Australia & The state road network including traffic regulation and access for freight vehicles \\
\hline Austria & Planning, financing, maintaining and tolling the entire Austrian motorway \\
\hline England & Responsible for operating, maintaining and improving the strategic road network \\
\hline Finland & Management of public road, railway and waterway networks. \\
\hline Germany & Research is mentioned, not a usable answer \\
\hline Ireland & To secure the provision of a safe and efficient network of national roads \\
\hline Lithuania & Maintenance and construction of roads of national significance \\
\hline Netherlands & $\begin{array}{l}\text { Asset management of main road, water network and navigation network, traffic } \\
\mathrm{mgt}\end{array}$ \\
\hline Scotland & $\begin{array}{c}\text { Rail and trunk road networks and maintaining the trunk roads and local roads } \\
\text { policy }\end{array}$ \\
\hline
\end{tabular}


Table 6 L2 road agency performance areas per country

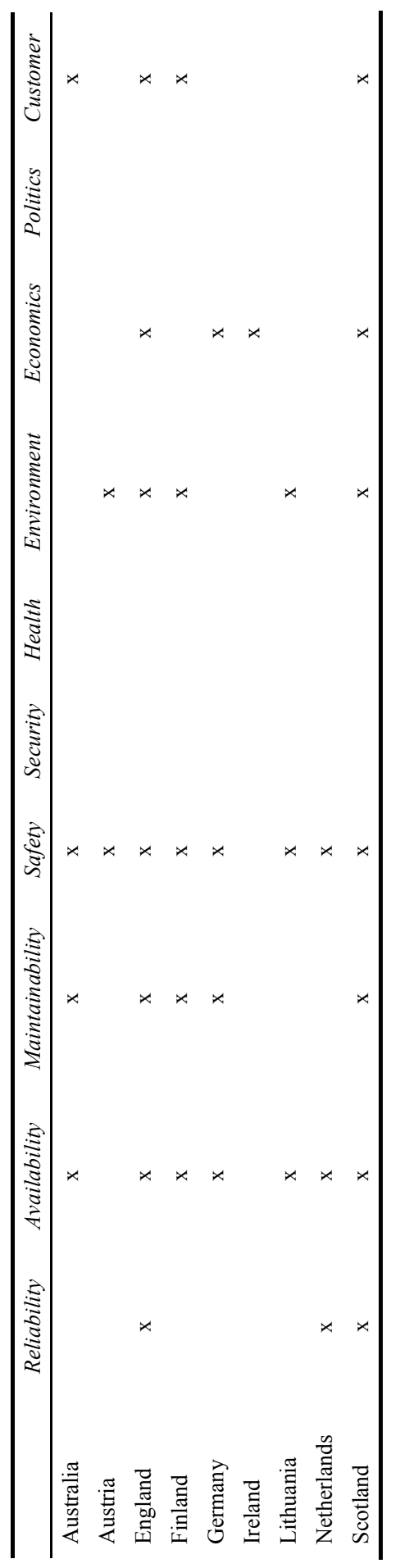


Table 7 L2 road agency performance measures per country

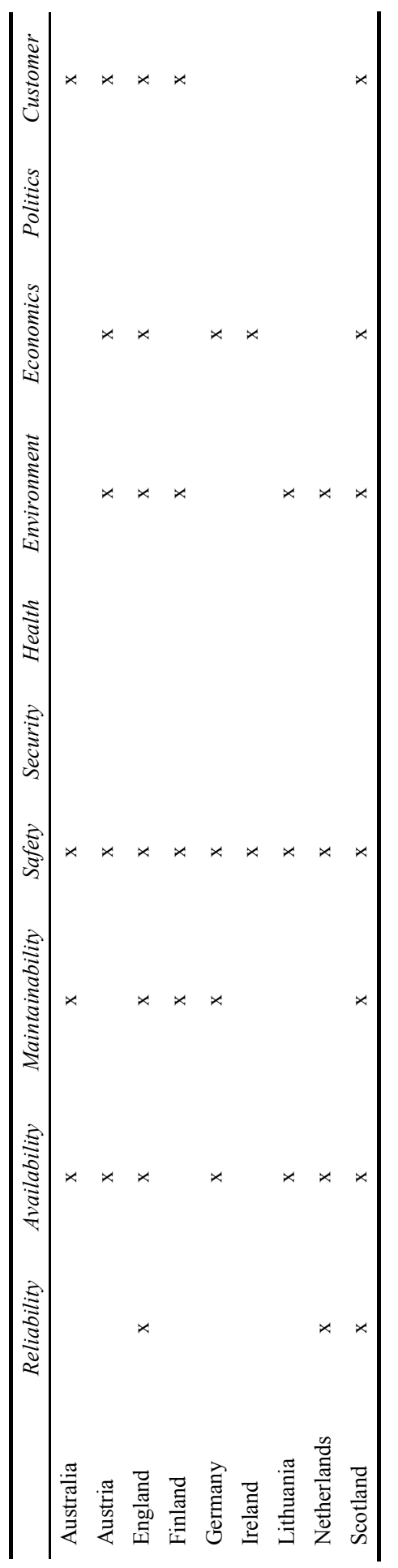


Maintenance, although not explicitly defined, is the central responsibility of all agencies. Operation of the network, managing traffic flows, is often mentioned but it is not always clear whether or not this is the explicit responsibility of the road agency. Based on the survey answers, it shows that responsibility of the road agency is limited to maintaining the network. Decision-making about expanding the network lies with the government. The responsibilities of the road agencies are reflected in the way the objectives of these organisations are formulated. Interesting is the use of some verbs in the goals, like facilitate growth (Australia) and enable safe travel (Finland). These verbs signal the limited responsibility of the road agency in achieving this objective.

\subsection{L2 road agency performance areas}

The agencies have developed performance measures for different areas. Table 6 lists the different areas for PM as stated by the different agencies. The areas for performance measures differ widely per country (see Table 6). Scotland has defined performance measures for seven different areas of PM: whereas Ireland predominantly focuses on costs.

Safety is the performance area that was mentioned most. No performance measures were defined for security, health, and politics. In the Dutch case, a distinction is made between the performance measures that are directly related to the activities of the road agency, and performance measures that are related to objectives of the government and for which the road agency is not fully accountable.

The Australian performance areas: office of road safety, road management, and state development are not stated in the table, because they could not be directly linked to a category.

\subsection{L2 road agency performance measures}

The areas of performance management are not all be operationalised into performance measures. The actual performance measures used as reported by the different agencies are listed in Table 7.

None of the agencies report performance measures that can be placed under security, health and politics. Safety, availability, environment, economics, and customer are frequently mentioned. In Finland, for example, the performance measures with respect to the customers are divided into three measures: customer satisfaction, satisfaction of business and industry, satisfaction of stakeholders. In England, the cost of operating, cost of maintaining and percentage of project spending that is good value for money are monitored. The performance measures used by the different countries are predominantly quantitative. Some countries use extensive lists of performance indicators, like Australia, Scotland and England. Others, like Ireland or Lithuania, make use of a small number of indicators.

\subsection{L2 road agency - indicator structure - combining and weighing of indicators}

- Combining indicators: Top-level indicators are usually a combination of lower level indicators. The question is to what degree road agencies are using combined 
indicators for their performance measures. It shows that predominantly individual indicators are used as performance indicators. The Scottish road agency notes that none of the PI's are combined, however, they seem to be combined to form part of the overall asset management objective. The Netherlands is the only country where all indicators relate to RAS of the RAMS-criteria and are in essence combined indicators. The Irish road agency noted that, while all indicators are individual, they can have an effect on each other, e.g., improved skidding resistance could lead to lower collision frequency. This is in fact part of the line-of-sight.

- Weighing of indicators: When combining indicators the relative importance of the underpinning indicators is not necessarily equal. This calls for some sort weighting before the indicators are combined. The survey shows that nearly all of the road agencies are currently not using weighing factors for their performance indicators. England, however, uses a system for weighing the performance indicators before combining them. Scotland will start to use weighting factors for the performance indicators and is currently discussing possible ways forward.

\subsection{Performance management application}

PM can have different functions. This section gives the survey results of the possible application of PM. We looked at target setting, budget negotiating, decision-making, reporting and sanctioning. These categories are an operationalisation of the functions mentioned in Section 2 approach.

- Target setting: All road agencies set annual targets and Scotland, Finland, Austria and Lithuania set longer-term targets. In Scotland, for example, the targets are discussed and agreed with stakeholders in a workshop environment. They may well change overtime as knowledge and experience is gained. The Dutch road agency negotiates the targets of their performance measures with the government before signing of the four-year SLA. In England, no targets are set between L1 and L2. In the past targets were, but from the beginning of the new coalition government only measures are used. From financial year 2013/14, a 'performance specification' will be used, with a mixture of targets and measures depending on the outcome to be achieved. The targets are set at agency level and will be cascaded down to individual team and contractor measures (L3).

- Budget negotiating: Most the countries do not use performance measures in their budget negotiations. Finland does, but indicates that the effect is minimal. The Netherlands is the only country currently prioritising/allocating budgets based on performance measures. In England, recent work around the new performance specifications for the agency made the funding position of the agency clearer: performance can only be delivered at a certain funding level. Scotland and Ireland see possibilities to use performance measures in the future to influence budgets and allocate budgets.

- Decision-making: Most of the road agencies do use the performance measures in their decision-making processes. Examples of this application come from Austria and England. Austria uses the customer criteria and the road safety objectives as the key aspects in their decision-making processes, of course balancing this with the annually available financial means. In England, at government level, measures such 
as cost, sustainability and employment impact are used to score and decide on major projects the road agency will deliver. As an input the agency advises on the cost/benefit ratio of the proposed schemes. Not all countries use performance measures for decision-making. In Scotland, the performance measures are currently used in decision-making with the exception of the performance measures that are in use at L2-L3 level (the contract key performance indicators). In Australia, performance management is not used in decision making for new transportation assets. The decisions are largely the result of multi-agency studies and are highly influenced by state and local politics.

- Reporting - creating transparency: Most of the road agencies report on an annual basis on how their network has performed. Finland is the only exception, reporting only on a quarterly basis. England reports on a monthly basis, with more formal discussions at a less frequent basis. Australia has a different and more extensive reporting regime compared to the European countries, the road agency reports on an annual, biannual and quarterly basis, but on top of that they are obliged to report ad hoc on request of the federal government or AustRoads. Austria is reporting on an annual basis in their annual report related to their 'core business', however, concerning other topics the Austrian road agency is responsible for, they are reporting to the involved departments of the Ministry on a more regular basis (i.e., road safety). In the Netherlands, the reporting is done in two progress reports and one annual report. The latter is leading; the other two reports are concerned to be an indication of network performance of the progressing year.

- Penalties - sanctioning: None of the road agencies are penalised for non-compliance to the targets of the performance measures. There are some exceptions. In Austria, the government can intervene in the operational business of the agency through variable remuneration of the management. Overall, however, no penalties are used. In Scotland, performance measures are not used for sanctioning at L1-L2 level. At L2-L3 level, however, the contract key performance indicators are used to encourage service improvement and delivery. In Finland, there is no formal penalty/bonus system at L1-L2 level. There used to be a bonus system at regional level, but that was abolished several years ago.

\subsection{PM evaluation}

- Agency experience with PM: According to the survey data the agencies have developed their PM programs over the last 10 years. Agencies in Australia, Austria, Finland, Lithuania and England have ten or more years of experience with their programme.

- Positive and negative PM experiences: The agencies encounter both positive and negative experiences. The overall picture shows that PM brings more clarity/gives more insight in the highway network policy. The clarity in (multiple-year) agreements, the objectivity of the measures, the clarity in the choice of projects, the need for maintenance expenditure and the guidelines for evaluation all show improved transparency. England also lists benefits such as transparency of spending taxpayers' money, enhanced project delivery and reputation, innovation and 
continuous improvement, and the need for objective, consistent, fair and motivational performance indicators.

An overview of the positive experiences is given in Table 8 .

Table 8 Positive experiences with PM per country

\begin{tabular}{ll}
\hline Country: & Positive experience with PM: \\
\hline Australia & Data used in developing the PM is useful at an operational level. \\
& PM's are used internally on an informal basis separately from external use. \\
Austria & Objectification of measures. \\
& Optimisation of measures and strategies. \\
England & PM has focused activities on achieving results and makes the agency better at \\
achieving outcomes with better alignment of resources with desired & outputs/outcomes. \\
& $\begin{array}{l}\text { Setting of targets across the full range of activities has ensured no significant area } \\
\text { overlooked. }\end{array}$ \\
Finland & $\begin{array}{l}\text { PM helps to show what is important, harmonises activities around the country } \\
\text { and helps in communication. }\end{array}$ \\
Ireland & $\begin{array}{l}\text { PM gives clarity in the choice of projects, demonstrates need for maintenance } \\
\text { expenditure and improves focus on financial management. }\end{array}$ \\
Lithuania & $\begin{array}{l}\text { PM helps determine needs of special measures, to evaluate with criteria's across } \\
\text { entire network and to set targets to be achieved in period of time }\end{array}$ \\
Netherlands & $\begin{array}{l}\text { Clear guidelines for the evaluation of the network performance, increased } \\
\text { accountability. }\end{array}$ \\
& Clear insight multiple year agreements.
\end{tabular}

Table 9 Negative experiences with PM per country

\begin{tabular}{ll}
\hline Country: & Negative experience with PM: \\
\hline Australia & $\begin{array}{l}\text { High-level measures are generally non-sensitive, benefit outcomes can be } \\
\text { misinterpreted due to business rules and data management. }\end{array}$ \\
Austria & PM is considered as a goal; instead of a way to achieve goals. \\
England & $\begin{array}{l}\text { Recording and reporting can be resource-intensive and may not necessarily } \\
\text { generate data useful for decision-making - too many measures may obscure the } \\
\text { key areas of concern. }\end{array}$ \\
& $\begin{array}{l}\text { Poorly framed targets may either be unachievable, leading to loss of morale, or } \\
\text { too easily achieved, leading to complacency. }\end{array}$ \\
& $\begin{array}{l}\text { PM is heavily reliant on having good data and it is important to ensure scores are } \\
\text { backed up by evidence. }\end{array}$ \\
& $\begin{array}{l}\text { PM does not cover all activities, it promotes short-term thinking and gives a too } \\
\text { simple picture }\end{array}$ \\
Finland & Difficult to score social benefits of a non-engineering type \\
Ireland & As the network is diverse - difficult to get consistent sections. \\
Lithuania & $\begin{array}{l}\text { Extra cost of PM. } \\
\text { Netherlands }\end{array}$ \\
& $\begin{array}{l}\text { Measures can be interpreted differently than intended and need be explanation } \\
\text { before use and rely on expert judgement }\end{array}$ \\
\hline
\end{tabular}


The listed negative experiences (see Table 9), differ from agency to agency but most of the perverse effects known from literature are mentioned, like short-term thinking, single sided focus, loss of ambition and misinterpretation. The cost of collecting and interpreting data is also mentioned by more than one agency. Australia mentions the negative experience of non-sensitivity of the high level (strategic) performance measures.

\section{Analysis}

The main question of this study is how government and road agencies have created an alignment between the objectives, performance areas and performance measures across different organisational levels. The second question is to what degree some sort of structuring, in this case categorisation according to RAMSSHEEP, can help in identifying and creating a line-of-sight.

\subsection{Visibility of line-of-sight and application of PM}

A relation between government objectives and road agency objective does not consistently show in Tables 3 and 4. For a clear line-of-sight one would expect identical listings in Tables 3 and 4. Part of the explanation could lie in the fact that government objectives generally are broader than the responsibilities of the road agency cover. While the government responsibilities include decision-making about improving and expansion of the network, responsibilities of the road agencies are more limited to execution of those projects and maintenance and operation of the infrastructure (see Table 5). Achieving the government goals is often not fully within the remit of the road agency. Apart from limited responsibilities, the road agency also has limited enforcement, and may depend on cooperation with others. This complicates a clear line-of-sight between government and agency objectives. This is a logical consequence of the requirements of a good performance indicator. An indicator for which you are held responsible, but that cannot be (fully) influenced by you is less legitimate. However, a road agency may be best placed to measure this indicator, in such a case the indicator is used for transparency only and the road agency cannot be held (fully) accountable for meeting the targets of this indicator.

Finding a relation between performance area and measure also shows to be problematic. One would expect that a PM in Table 7 can only be listed if it is also listed as an area in Table 7. Several measures are listed in Table 8 where there is no enlisted area for it in Table 7. Therefore, the relation between performance area and measure are not always clear.

The top-level indicators are a combination of lower level indicators. When combining indicators the relative importance of the underpinning indicators calls for some sort of weighing of the individual indicators. The survey only identified a structured approach in combining and weighing indicators at the English road agency and the intention to do so at Scottish road agency. 
- Examples of line-of-sight: A clearer line-of-sight between L1-L2 and within L2 can be seen with respect to the performance measure areas of Australia, Scotland and England (but only if we do not look at them with RAMSSHEEP in mind). In general, government objectives are not systematically translated into objectives of the road agency. But these countries have made progress in this area. The areas of performance have been clearly operationalised into measurable performance measures as the principle shows in Figure 3.

- Applications of PM: The survey shows a limited application of PM. Theory identifies five functions of PM. Of those five functions only transparency is clearly present through the reporting that all agencies do. Sanctioning is not applied anywhere. Although most countries apply target setting for their performance measures, there is only limited use of those measures for budget negotiating and decision-making. Clearly there are other factors influencing the decisions and height of the budgets.

- Experience with PM: Most countries have several years of experience and have developed PM systems over ten or more years. Overall, there are positive experiences with the systems; it clearly creates more transparency, helps to objectify measures, to create consistency and supports decision-making. The survey revealed some of the predicted negative effects of PM. The most frequent effects are misinterpretation and short term focus and the difficulty in explaining the philosophy behind measures.

Figure 3 Example of alignment within L2 for Transport Scotland

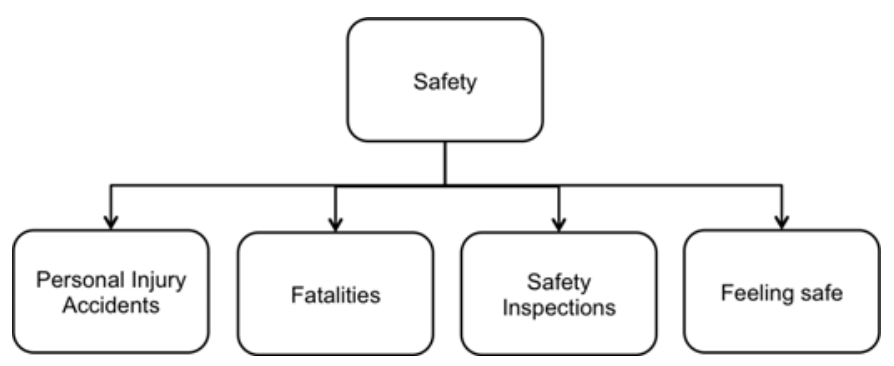

Source: Based on: Arran (2003), received as part of a survey

\subsection{Application of RAMSSHEEP}

The RAMSSHEEP categorisation, as aspired to by RWS, does not assist in showing the line-of-sight at L1-L2 level.

To illustrate this, we use an Australian example. Table 10 lists the government and road agency objectives as we received them from the survey response after RAMSHEEP categorisation. No line-of-sight is visible. In case of a line-of-sight, the ' $x$ ' should appear in more than one row in a column. The difference between the rows within a column is the number and definition of the indicators represented by the single ' $x$ '. 
Table 10 Australia - MRWA - no clear line-of-sight using RAMSSHEEP

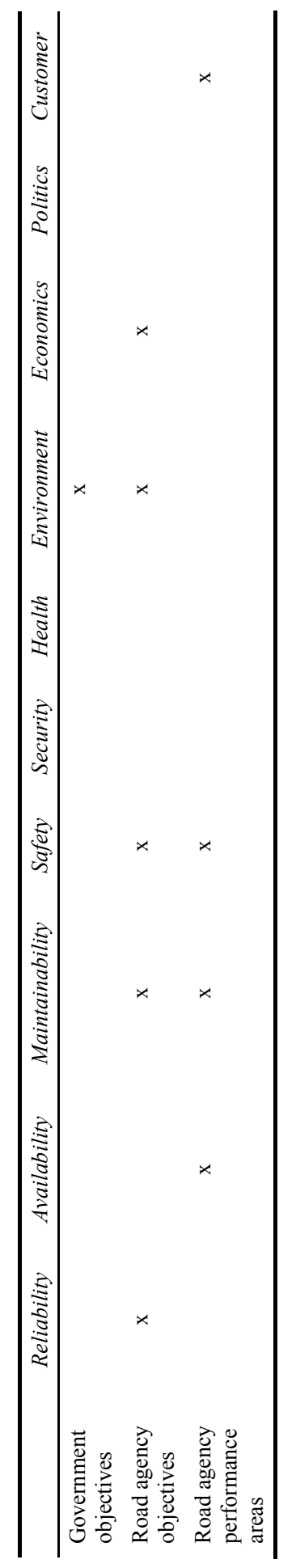


Table 11 Government objectives and road agency objectives

\begin{tabular}{lcc}
\hline Government goals & Main roads outcomes & Main roads programme \\
\hline $\begin{array}{l}\text { Outcomes-based service } \\
\text { delivery }\end{array}$ & A safe road environment & Road safety \\
& $\begin{array}{c}\text { Reliable and efficient movement } \\
\text { of people and goods }\end{array}$ & $\begin{array}{c}\text { Office of road safety } \\
\text { Road management } \\
\text { Road efficiency }\end{array}$ \\
$\begin{array}{l}\text { State building - major } \\
\text { projects }\end{array}$ & $\begin{array}{c}\text { Facilitate economic and regional } \\
\text { development }\end{array}$ & State development \\
$\begin{array}{l}\text { Stronger focus on the } \\
\text { regions }\end{array}$ & A well maintained network & Maintenance \\
$\begin{array}{l}\text { Social and environmental } \\
\text { responsibility }\end{array}$ & $\begin{array}{c}\text { Improved community access and } \\
\text { roadside amenity }\end{array}$ & Community access \\
\hline
\end{tabular}

Source: MRWA (2010)

Table 11 shows the government objectives and road agency objectives for MRWA. While the government objectives and road agency objectives are linked the alignment at government level is in some cases directly translated into an agency outcome. E.g., 'stronger focus on regions' is at agency level translated into a 'well-maintained network'. This way of aligning suggests that a well maintained network can be translated directly into a stronger focus on the regions. The government goal 'delivery' is translated into MRWA outcomes 'reliable and efficient movement of people and goods'. This government goal has been translated into two different main roads outcome and shows a clearer hierarchy according to Keeney (1996).

The Australian example illustrates that the RAMSSHEEP categorisation is less suitable at this higher aggregation level. Government objectives are defined at a much higher aggregation level than the RAMSSHEEP criteria.

\section{Conclusions}

All governments and road agencies that participated in the study use PM. In general, the government objectives are not clearly aligned with agency objectives and performance areas. This limited line-of-sight issue is a complicating factor in the determining the effectiveness of the measures.

- Use of performance management is an organisational learning process: The experience in developing and implementing objectives within agencies is less than ten years in most cases. The more experienced agencies show a more mature system of performance measures that the less experienced. This has also resulted in a better line-of-sight within the more experienced road agencies: from organisational objectives to performance areas and performance measures. A few (Anglo-Saxon) countries can serve as an example: Scotland, Australia, and England.

- The RAMSSHEEP approach is not fully applicable at L1-L2 levels: Government objectives are aggregated, multi-valued concepts. This makes the RAMSSHEEP categorisation less applicable at government level (L1). The RAMSSHEEP 
categorisation seems to be applicable within L2 and lower - at regional or contractual (service provider) level. The RAMSSHEEP is less applicable to use as a line-of-sight to government level (L1) because of the lack of discriminating detail in these criteria.

- Improving the line-of-sight: The analysis shows a limited line-of-sight between government objectives and road agency performance measures. There is ample room for improvement at most road agencies. The use of a Hierarchical Performance Management approach (HPM, see Figure 4) is a good alternative. This approach can be applied without the need to strictly abide to the RAMSSHEEP categorisation. The focus should not merely be hierarchical system of performance management but should also pay attention to the conditions for a well-designed and accepted process of measuring performance (Keeney, 1996).

Australia and England, have ongoing development of multi-scaled indicators, whole-of-life indicators, performance flags, scoring propagation and value-functions as the basis for creating weighted (aggregated) indicators (de Bruijn, 2007; Schoenmaker et al., 2011; van der Lei and Ligtvoet, 2012) These may help in supporting road agencies in improving their line-of-sight.

- Application of PM and perverse effects: As said, PM can be used for various functions. It is important to make a conscious and clear choice in the function of the PM system to avoid perverse effects. It is very important to define the purpose of PM well and both parties must agree to the function of PM. This survey has shown that all agencies experience perverse effects of PM. Further research should gather more data on the experience of the using a PM system and the actions that the agencies have taken to prevent or mitigate the effects of the perverse effects.

Figure 4 Principle of hierarchical performance management

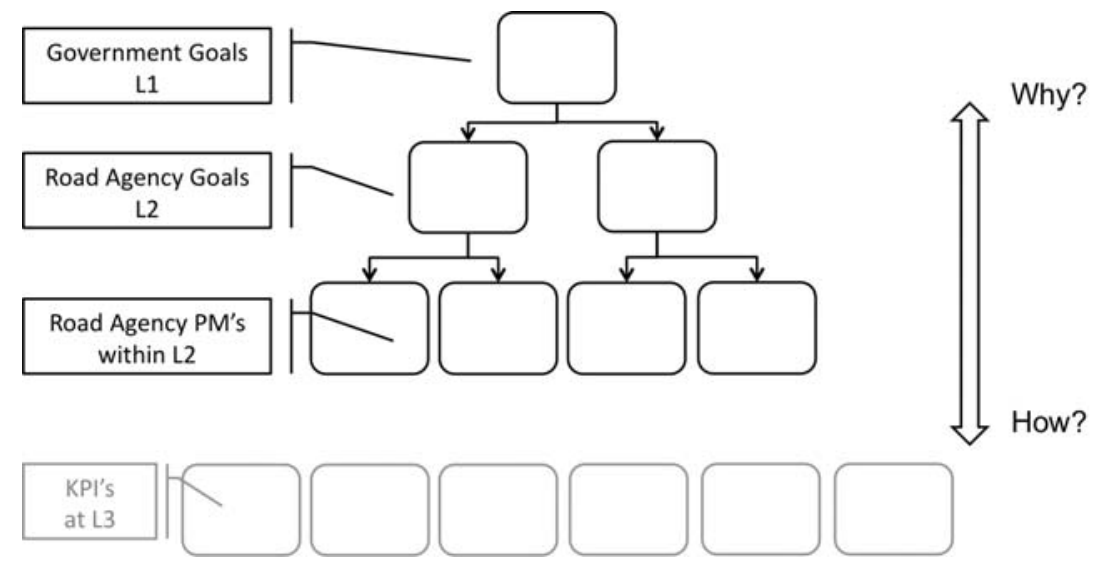




\section{References}

Altamirano, M.A. (2010) Innovative Contracting Practices in the Road Sector, $\mathrm{PhD}$, Technische Universiteit Delft, Delft.

Arran, D. (2003) Transport Scotland Approach to Asset Management, Transport Scotland, Glasgow.

Bouckaert, G. and Auwers, T. (1999) Prestaties meten in de overhead, die Keure, Brugge.

BSI Group (2012) Draft BS ISO 55000 Asset Management - Overview, Principles and Terminology, BSI Group, London.

CENELEC (1999) EN 50126 Railway applications - The specification and demonstration of Reliability, Availability, Maintainability and Safety (RAMS): Part 1: Basic requirements NENEN 50126, p.92, NEN, Delft.

de Bruijn, J.A. (2006) Prestatiemeting in de publieke sector: Tussen professie en verantwoording, Lemma, Utrecht.

de Bruijn, J.A. (2007) Managing Performance in the Public Sector, Routledge, Utrecht.

FHWA (2010) Linking Transportation Performance and Accountability FHWA-PL-10-11, Alexandria, VA.

Hall, J.W., Le Masurier, J.W., Baker-Langman, E.A., Davis, J.P. and Taylor, C.A. (2004) 'A decision-support methodology for performance-based asset management', Civil Engineering and Environmental Systems, Vol. 21, No. 1, pp.51-75.

Hodkiewicz, M., Hall, A., Johnston, D. and Baron-Croston, J. (2013) Composite Indicator for Whole of Life Management, UWA, Perth.

INCOSE (2010) INCOSE Systems Engineering Handbook v3.2.2 [online] http://www.incose.org (accessed January 2012).

Karlaftis, M. and Kepaptsoglou, K. (2012) 'Performance measurement in the road sector: a cross-country review of experience', in I.T. Forum (Ed.). OECD, Athens, Greece.

Keeney, R.L. (1996) Value-Focused Thinking: A Path to Creative Decision-Making, Harvard University Press, Cambridge, MA.

Koppinen, T. and Lahdenpera, P. (2004) Road Sector Experiences on Project Delivery Methods, VTT, Helsinki.

Main Roads Western Australia (MRWA) (2010) Making Roads Work-Annual Report 2010, Perth.

NCHRP (2006) Performance Measures and Targets for Transportation Asset Management, Vol. 551, Transportation Research Board, Washington, DC.

NCHRP (2009) Transportation Performance Management: Insight from Practitioners, Vol. 660, Transportation Research Board, Washington, DC.

NCHRP (2010) Target-Setting Methods and Data Management to Support Performance-Based Resource Allocation by Transportation Agencies, Vol. 666, Transportation Research Board, Washington, DC.

NCHRP (2012) Performance-Based Highway Maintenance and Operations Management, Vol. 426, Transportation Research Board, Washington DC.

OECD (2008) Handbook on Constructing Composite Indicators - Methodology and User Guide, OECD, Paris.

Pakkala, P.A., de Jong, W.M. and Äijö, J. (2007) International Overview of Innovative Contracting Practices for Roads, Finnish Road Administration, Helsinki.

Queiroz, C. and Kerali, H. (2010) A Review of Institutional Arrangements for Road Asset Management: Lessons for the Developing World, The World Bank, Washington DC.

Rijkswaterstaat (RWS) (2009) DBFM Agreement, Directorate-General for Public Works and Water Management, Den Haag.

Schoenmaker, R. (2011) De ingeslagen weg (The Chosen Way), PhD, Delft University of Technology, Delft. 
Schoenmaker, R., de Bruijn J.A. and Herder P.M. (2011) 'The dynamics of outsourcing maintenance of civil infrastructures in performance-based contracts', Paper presented at the World Conference of Engineering Asset Management, Cincinnati, $\mathrm{OH}$.

Schraven, D., Hartmann, A. and Dewulf, G. (2011) 'Effectiveness of infrastructure asset management: challenges for public agencies', Build Environment Project and Asset Management, Vol. 1, No. 1, pp.61-74.

Smith, P. (1995) 'On the unintended consequences of publishing performance data in the public sector', International Journal of Public Administration, Vol. 18, No. 2, pp.277-310.

van der Lei, T. and Ligtvoet, A. (2012) 'Value focused thinking; an approach to structure company values for asset management', Paper presented at the WCEAM, Deajeon, Korea.

van Dooren, W. (2006) Performance Measurement in the Flemish Public Sector: A Supply and Demand Approach, K.U. Leuven, Leuven.

Verweire, K. and van den Berghe, L. (Eds.) (2004) Integrated Performance Management - A Guide to Strategy Implementation, Sage, London.

Waggoner, D.B., Neely, A.D. and Kennerley, M.P. (1999) 'The forces that shape organizational performance measurement systems: an interdisciplinary review', International Journal of Production Economics, Vols. 60-61, pp.53-60.

\section{Appendix}

Towards a line-of-sight, Implementation of Performance Measurement by Road Agencies: A European and Western Australian Perspective.

\section{Questionnaire}

Part 1 General information

Country/state.

Organisation.

Address.

Telephone number.

E-mail address.

Name and function.

Your role within the organisation and area of knowledge.

Part 2 Identification of goals/objectives

What are the goals/objectives of your government in the field of (road) transportation?

What are the goals/objectives of your agency?

What are the responsibilities of your agency?

For what aspects of road transportation infrastructure asset management is your organisation held accountable?

What is the primary motivation in your agency for establishment of performance goals? 


\section{Part 3 Identification of PM's}

Which areas for performance measures (PM's) are identified in your state/country?

Please list for each area the PM's your agency is using.

Which indicators used by your agency are individual performance indicators (PI) and which are combined indicators, either from the same indicator across various parts of the network or from various indicators from the same part of the network?

In case of composite/combined PI: Are there weighing factors involved?

How did/does your agency establish the performance measures and targets?

Part 4 Application of performance management

Are targets being set for each PI within your organisation?

On which level are the targets set?

How are targets set in (new) contracts for maintenance and/or new roads?

Does your state/country use incentives or penalties to penalise your agency?

What is the frequency of PM reporting to the government of your agency?

Are PM's used in decision making with respect to maintenance, rehabilitation, renovation and new built of transport infra?

What is the top three of PM's used in decision making?

How does the agency communicate the performance measures and targets to the public?

Part 5 Evaluation of performance management

How long is your organisation using PM?

What are your organisation's positive and negative experiences in working with PM?

Has the performance and condition of the road transportation network improved by using PM?

Is PM being used in the budget negotiations with the financial department?

Does the Agency have a means of evaluating the effectiveness of performance measures?

Are ineffective performance measures removed or modified?

On what frequency are performance measures and targets reviewed for possible update?

Part 6 Evaluation of the PM survey

Do you have any comments on this survey in general or do you want to add some information on the subject which was not covered by the survey?

Would you mind answering some additional questions in the near future regarding this subject?

Is there any additional literature (or websites) available in your country on this subject which you want to share with us? 